\title{
Mídias sociais na administração pública: um estudo sobre a utilização do Facebook pelos municípios do Recôncavo do estado da Bahia - Brasil
}

\author{
Social media in public sector: a study about the use of Facebook by municipalities in the Reconcavo \\ region in the Bahia State, Brazil
}

\section{Adriano Santos Rocha Silva}

Universidade Federal de Sergipe - UFS, Departamento de Administração - DAD, Av. Marechal Rondon, s/n, Jardim Rosa Elze, CEP 49100-000, São Cristóvão, SE, Brasil, adrianorocha70@gmail.com

\section{Emmanuelle Fonseca Marinho de Anias Daltro}

Universidade Federal da Bahia - UFBA, Núcleo de Pós-Graduação em Administração - NPGA, Av. Reitor Miguel Calmon, s/n, Vale do Canela, CEP: 40110-903, Salvador, BA, Brasil, lelledaltro@msn.com

\section{Ernani Marques dos Santos}

Universidade Federal da Bahia - UFBA, Núcleo de Pós-Graduação em Administração - NPGA, Av. Reitor Miguel Calmon, s/n, Vale do Canela, CEP: 40110-903, Salvador, BA, Brasil, emarques@ufba.br

\section{José Henrique Paraguassu Oliveira}

Universidade Federal da Bahia - UFBA, Núcleo de Pós-Graduação em Administração - NPGA, Av. Reitor Miguel Calmon, s/n, Vale do Canela, CEP: 40110-903, Salvador, BA, Brasil, jhparaguassu@gmail.com

\begin{abstract}
Resumo
0 presente estudo analisa a utilização das mídias sociais por parte da administração pública municipal. Para tanto, foi realizada uma pesquisa quantitativa e descritiva, sendo a amostra composta pelos 20 municípios do Território Recôncavo, região do Estado da Bahia, no Brasil. Referente às mídias sociais, optou-se por pesquisar o uso do Facebook por ser este o maior e mais importante site de rede social utilizado no país. Foram observados os aspectos presença e tipo de inserção no Facebook, data da primeira postagem, quantidade de amigos ou seguidores, existência de identificação do administrador da fan page, conteúdos das postagens, interação com os usuários e adequação visual e da linguagem. Destacam-se nos resultados que 70\% dos municípios pesquisados utilizam o Facebook de modo oficial, sendo a primeira postagem em 2010. Mas, apesar da capilaridade proporcionada pelas mídias sociais, os amigos ou seguidores correspondem a apenas $2,5 \%$ da população da região estudada.
\end{abstract}

Palavras-chaves: Mídias sociais, administração pública, Facebook, Recôncavo da Bahia, Brasil.

\begin{abstract}
This study analyses the use of social media, especially the Facebook, by local governments. A quantitative and descriptive research was conducted collecting data from the 20 municipalities located in "Território Recôncavo", a Bahia State area, in Brazil. The observed aspects were: kind of presence in Facebook, date of the first post, number of friends/followers, page administrator identification data, post contents, level of interactivity with users, and visual and language use. The results point out that $70 \%$ of the researched municipalities use the Facebook as an official communication tool, some of them since 2010. However, although the use of social media allows to reach a high audience, the number of page friends/followers corresponds to only $2.5 \%$ of the population of the region.
\end{abstract}

Keywords: Social media, public sector, Facebook, Bahia Recôncavo Area, Brazil.

\section{Introdução}

Dentre as mudanças introduzidas no Brasil pela Reforma Gerencial do Estado, de 1995, observam-se ações e intenções que visam o aperfeiçoamento das relações entre o poder público e os cidadãos no âmbito de suas atribuições institucionais. Nesse processo, um dos pontos vitais envolve a comunicação entre as partes, seja para o poder público informar ações e prestar contas à população, seja para o cidadão emitir sua opinião, reclamar ou pedir esclarecimentos.

Concomitantemente às mudanças na estrutura da administração pública em suas diversas esferas, decorrentes da Reforma Gerencial, ocorreu o advento da chamada Web 2.0 e ainda tem ocorrido uma considerável expansão da informatização das organizações. Esta nova concepção de uso das tecnologias da informação como meio de proporcionar interação entre usuários e desenvolvedores tornou as emergentes mídias sociais potenciais canais de comunicação devido à sua flexibilidade, rapidez e alcance, além da possibilitar o compartilhamento de conteúdos (Saad Correa, 2009). Prova disso é o número crescente de empresas de todos os portes e órgãos públicos que têm lançado mão das mídias sociais para se comunicar com seus respectivos públicos. Um exemplo são as prefeituras municipais, notadamente as do interior, que têm encontrado nas mídias sociais a rapidez e versatilidade necessárias para se comunicar com seus cidadãos com um custo suficientemente baixo para não comprometer seus orçamentos.

No âmbito acadêmico, diversos autores têm se debruçado sobre o tema mídias sociais, sendo que alguns estudos o relacionam com o contexto da esfera pública. Contudo, o assunto ainda está longe de ser esgotado, existindo lacunas de conhecimento. Na esfera municipal, pode-se questionar, por exemplo, se as administrações públicas municipais realmente têm lançado mão das mídias sociais, ou quais as reais motivações de usar as mídias sociais do ponto de vista 
das prefeituras, ou ainda quais os resultados esperados com essas ações.

O Brasil é uma República Federativa constituída de 27 estados e um distrito federal (a capital, Brasília), agrupados geograficamente em cinco regiões (Norte, Nordeste, Sul, Sudeste e Centro-Oeste). Cada estado é, por sua vez, composto por grupos de cidades, chamadas municípios. Ao se observar o Estado da Bahia, está se tratando de um universo de 417 municípios, sendo que, com exceção da capital Salvador e da cidade de Feira de Santana, classificadas pelo Instituto Brasileiro de Geografia e Estatística [IBGE] como metrópole e cidade grande, respectivamente, todos se enquadram nos perfis de cidade média ou pequena. Ainda segundo o IBGE (2013), as populações dos municípios baianos apresentam uma imensa variação, chegando a cerca de 2,9 milhões de habitantes na capital, a meros 3,4 mil habitantes na cidade Catolândia. O IBGE aponta que, em 2013, exatos 400 municípios baianos possuíam menos de 100 mil habitantes.

É exatamente diante das características tão díspares dos municípios baianos relacionadas às lacunas anteriormente citadas que este estudo se propõe a responder à seguinte pergunta: de que maneira os municípios baianos têm utilizado as mídias sociais como meio de comunicação oficial? A resposta a esta questão permite se obter uma visão mais real de como a administração pública municipal tem utilizado as mídias sociais para se comunicar com seus cidadãos e que tipo de informação transmitem por meio dessas mídias. Tais resultados mostram-se relevantes para um melhor planejamento e desenvolvimento por parte daqueles que trabalham diretamente com comunicação pública oficial, assim como para pesquisadores e profissionais que lidam com o assunto mídias sociais, suas aplicações e tendências.

\section{Revisão da literatura}

\subsection{Mídias sociais}

Segundo Boaria, dos Anjos e Raye (2014), o surgimento e aperfeiçoamento da internet proporcionou o desenvolvimento e aperfeiçoamento das tecnologias da informação e comunicação. Dentro deste contexto, o que se conhece hoje como mídias sociais é parte dessa evolução. Arnaut et al. (2011, p. 262) argumentam que "mídia é qualquer forma ou meio utilizado para a comunicação", incluídas aí as mídias tradicionais e sociais. Dizard (2000), por sua vez, complementa afirmando que as chamadas mídias tradicionais se constituem nos meios de comunicação em massa, a exemplo da televisão, cinema, rádio, revista e jornal. Esse tipo de mídia, ainda segundo o autor, mesmo com o crescimento e fortalecimento das mídias sociais e dos meios eletrônicos nos últimos anos, tende a continuar sendo por muito tempo o elemento mais importante do padrão mídia em termos do seu alcance e influência, mas estará sujeita a profundas e dolorosas mudanças à medida que precisar se adaptar a novas tecnologias, à mudança de comportamento do público e aos constantes desafios impostos pela Internet. Para o autor, a mídia tradicional deve permanecer como um "elo constante na transição para um novo ambiente de comunicação de massa" (Dizard, 2000, p. 257).
Por outro lado, as mídias sociais, segundo Kaplan e Haenlein (2010, p. 61), são um "grupo de aplicações para Internet, construídas com base nos fundamentos ideológicos e tecnológicos da Web 2.0, e que permitem a criação e troca de Conteúdo Gerado pelo Utilizador (UGC)". Em outras palavras, trata-se de uma ampla diversidade de meios de comunicação (mídia, portanto), baseados na Internet, que visam proporcionar um ambiente de participação e interação por parte do usuário, proporcionando-lhe a possibilidade de gerar, ampliar, enriquecer, organizar ou modificar as informações e conteúdos veiculados por essa mídia. É exatamente esta característica de interatividade e construção coletiva que distingue as mídias sociais das mídias tradicionais.

Enquanto nas mídias tradicionais o controle se concentra em um reduzido número de atores, como agências de publicidade, anunciantes e os veículos propriamente ditos, as mídias sociais possuem o controle disseminado entre seus usuários, quebrando a estrutura emissor-receptor e possibilitando que as informações sejam transmitidas de forma muito mais rápida (Recuero, 2009). Além disso, segundo Romano, Chimenti, Rodrigues, Hupsel e Nogueira (2012), e também diferente das mídias tradicionais, na Internet, a comunicação pode seguir diversas direções e alterar esses sentidos repentinamente, tornando sua tentativa de controle bem mais difícil, quando não inócua. Segundo os autores:

Esse é um desafio que boa parte das organizações enfrenta atualmente: lidar com o fenômeno da Internet e em especial com as Mídias Sociais Digitais (MSDs). Estas são plataformas que permitem a criação e o compartilhamento de conteúdo entre as pessoas, viabilizam a comunicação em larga escala, e vem ganhando cada vez mais destaque, impulsionadas principalmente pela crescente massa de usuários (Romano et al. 2012, p. 2).

Mídias sociais podem ter inúmeros e diferentes formatos, como, por exemplo, os blogs (publicações editoriais independentes), microblogs, (a exemplo do Twitter), salas de bate-papos, sistemas de compartilhamento de fotos e vídeos (a exemplo do Instagram e do Youtube), wikis (compartilhamento de conhecimento), e especialmente redes sociais mediadas por TI propriamente ditas, com destaque para o Facebook. Este foi considerado no ano de 2012 o maior e mais importante site de redes sociais no Brasil (Secretaria de Comunicação da Presidência da República [Secom], 2012) e liderava, em abril de 2013, a lista dos dez sites de redes sociais mais visitados, com 66,54\% (Serasa Experian, 2013).

O surgimento e o crescimento das mídias sociais, portanto, são decorrências do considerável avanço da tecnologia da informação (TI) desde, principalmente a última década do Século XX. Kaplan e Haenlein (2010) lembram que foi nos primeiros anos do Século XXI que surgiram as expressões mídias sociais e Web 2.0 (2004), mas a concepção e mesmo a utilização de mídias sociais pode ter sido criada vários anos antes. Segundo os autores:

By 1979, Tom Truscott and Jim Ellis from Duke University had created the Usenet, a worldwide discussion system that allowed Internet users to post public messages. Yet, the era of Social Media as we understand it today probably started about 20 years earlier, when Bruce and Susan Abelson founded "Open Diary," an 
early social networking site that brought together online diary writers into one community (Kaplan \& Haenlein, 2010, p. 60).

Segundo Romano et al. (2012, p. 4), "novas tecnologias levaram à criação do termo Web 2.0, entendido como plataforma para aplicativos e novos modelos de negócios baseados na interatividade e colaboração, continuamente atualizados pelos próprios usuários". Já para Recuero (2009), as mídias sociais permitem maior conversação e diversidade de fluxos de informação entre seus participantes, incentivando a emergência de redes sociais.

Existem múltiplas definições para mídias sociais desde que se configurou a Web 2.0. Dentre essas, pode-se estabelecer sua compreensão considerando que são quaisquer tecnologias ou práticas on-line que permitem o compartilhamento de conteúdo, opiniões, ideias, experiências e mídias, possibilitando conversações sobre o que é relevante. Destaquem-se os termos "compartilhamento" e "conversações", transformadores do modo tradicional de comunicação (Correa, 2009, p. 164).

Apesar de serem utilizados muitas vezes como sinônimos, os conceitos de mídias e redes sociais na Internet diferem. Conforme Arnaut et al. (2011), mídias sociais têm o foco no compartilhamento de textos, imagens, áudios e vídeos, muitas vezes utilizadas por organizações com fins comerciais, enquanto que as redes sociais apresentam como principal característica o relacionamento entre pessoas, mesmo permitindo também a inserção de textos, imagens, áudios e vídeos. As redes sociais, conforme os autores, constituem-se em um subgrupo das mídias sociais, mudando apenas a finalidade de cada uma. Vale lembrar que a expressão aqui utilizada se refere a redes sociais mediadas por TI.

Para Storch (2007), as redes sociais hoje são imprescindíveis para o fluxo de informações, para a construção do conhecimento e para a difusão de opiniões, sendo que o domínio das técnicas de análise de redes sociais pode contribuir de modo significativo na formação de equipes para processos de inovação, inteligência de mercado e tomada de decisão.

Smith (2009) classifica as redes sociais como sendo um fenômeno global que está se espalhando pelo mundo, tendo se tornado uma importante ferramenta de marketing. As redes sociais estão proporcionando às organizações novas ferramentas de segmentação de campanhas de acordo com os perfis de seus usuários e comunidades, tornando possível o desenvolvimento de relacionamentos personalizados e em larga escala ao mesmo tempo (Secom, 2012; Smith, 2009).

De acordo com Castells (2005), já há esforços de vários pesquisadores para se compreender a questão da sociabilidade nas redes eletrônicas e as consequências culturais dessa nova forma de interação social. 0 fato é que esse processo está totalmente imerso na sociedade informacional que estamos nos tornando e contribuindo para uma nova forma de organização social. "As novas tecnologias da informação estão integrando o mundo em redes globais de instrumentalidade. A comunicação mediada por computadores gera uma gama enorme de comunidades virtuais" (Castells, 2005, p. 57).
Segundo Marteleto (2010, p. 33), os estudos das redes trazem à tona um fato do mundo contemporâneo que ainda está pouco explorado, qual seja, "os indivíduos, dotados de recursos e capacidades propositivas, organizam suas ações nos próprios espaços políticos em função de socializações e mobilizações suscitadas pelo próprio desenvolvimento das redes".

\subsection{Comunicação oficial na administração pública municipal}

Em meados dos anos 1990, o governo federal brasileiro deu início à Reforma Gerencial do Estado, que trouxe, dentre outras tantas inovações para a época, a necessidade de uma comunicação mais eficiente e apurada entre o poder público e os cidadãos. O Plano Diretor da Reforma (Ministério da Administração Federal e Reforma do Estado [MARE], 1995, p 61), em sua proposta de Projeto Cidadão, considerava que o Estado deveria observar as necessidades da população, tanto no que se refere à "informação ao cidadão a respeito do funcionamento e acesso aos serviços públicos, e quaisquer outros esclarecimentos porventura solicitados", quanto ao "recebimento de reclamações e sugestões do cidadão sobre a qualidade e a eficácia dos serviços públicos que demandam uma resposta pró-ativa da Administração Pública a respeito".

Bresser Pereira, então ministro responsável pela reforma do Estado, baseia-se na figura do mercado e identifica o cliente da administração pública "não apenas como cliente, mas como um cliente cidadão revestido de poderes que vão além dos direitos do cliente ou do consumidor" (Bresser Pereira, 1999, p. 8). Para Motta (2007), só através de reformas que alterem os canais de comunicação, aproximando cidadãos e gestores públicos, será possível a efetiva modernização da administração pública brasileira. Neste sentido, observa-se que a nova gestão pública, pautada na eficiência, tem como figura central o cidadão e deve seguir a tendência de induzir a implantação de canais de comunicação qualificada com ele.

Rezende e Leite (2009), porém, têm o cuidado de distinguir gestão pública e gestão municipal. 0 conceito de gestão, sob a ótica da administração, está relacionado com o conjunto de tomadas de decisão, e seus respectivos recursos, e com a aplicação das atividades destinadas aos atos de gerir (Mintzberg, Ahlstrand \& Lampel, 2000). Sendo assim, os autores mostram o conceito de gestão pública, de forma sintética, relacionado ao processo decisório e à gestão das diversas funções de organizações públicas, seja no nível federal, estadual ou municipal, envolvendo a participação efetiva dos cidadãos nesse processo. A gestão municipal, por sua vez, entendida por Rezende e Leite (2009) como o gerenciamento da prefeitura municipal e suas secretarias, autarquias e demais órgãos, está relacionada com o conjunto de recursos e instrumentos usados pelos servidores municipais nas suas administrações (Rezende \& Castor, 2006).

\subsection{Mídias sociais na administração pública municipal}

Observando sob o ângulo da utilização de mídias e redes sociais pela administração pública, Kes-Erkul e Erkul (2009, 
p. 5) destacam que as mídias sociais têm a capacidade de proporcionar uma maior participação da comunidade. Segundo os autores, "Web 2.0 tools, such as social media have the capacity to change the relationship between the Internet and its users, and can change power structures and increase the opportunity for users to engage in greater community participation".

Danis et al. (2009), por sua vez, consideram que governos locais podem utilizar sites de mídia social para monitorar e resolver problemas, adquirir recursos e envolver os seus cidadãos em um clima de cooperação. Para Cole (2009, p. 9), "as mídias sociais são ferramentas de comunicação globais poderosas que podemos implementar para ajudar a rejuvenescer o engajamento cívico".

No cotidiano, é possível observar a tendência do uso de mídias sociais pelos agentes públicos e agentes políticos no âmbito da administração pública no Brasil. Segundo Pinto (2012), em 50\% dos órgãos públicos brasileiros o acesso às mídias sociais é totalmente liberado e em apenas $25 \%$ o acesso é totalmente proibido. Como este fenômeno é relativamente novo, são raras as situações em que o uso institucional da ferramenta está normatizado. Em 2012, foram estabelecidas diretrizes para o uso seguro das redes sociais na administração pública federal e, a partir deste marco, alguns órgãos têm se mobilizado no sentido de normatizar a utilização dessas mídias sociais, a exemplo da Secretaria de Comunicação Social da Presidência da República, que editou manuais de orientação (Conselho de Defesa Nacional [CDN], 2012; Secom, 2012).

Mais do que normatizar o uso de mídias sociais na gestão pública, porém, inúmeros órgãos da administração pública já têm utilizado as mídias sociais como meio de comunicação institucional, criando fan pages oficiais para divulgação de ações ou maior interação com os cidadãos (Secom, 2012).

Em nível internacional, um estudo da University of Illinois concluiu que em quase nove das dez maiores cidades dos Estados Unidos o Facebook e o Twitter foram utilizados pelos poderes públicos locais no ano de 2011 (Govtec, 2012). 0 mesmo estudo observou que entre as 75 maiores cidades americanas, $87 \%$ estavam usando o Twitter em 2011, em comparação com os 25\%, em 2009. O Facebook também foi utilizado por $87 \%$, em 2011, registrando um grande salto quando comparado aos $13 \%$, em 2009. 0 YouTube, por sua vez, foi um recurso utilizado pela gestão pública local em $75 \%$ das grandes cidades dos Estados Unidos, bem superior aos 16\%, em 2009.

\section{Metodologia}

Para o desenvolvimento deste estudo foi realizada uma pesquisa quantitativa descritiva, sendo a amostra composta pelos municípios que compõem o Território de Identidade do Recôncavo Baiano, região próxima a Salvador, capital do Estado da Bahia, localizado no Brasil. A escolha deste território deu-se em função da região ter uma alta concentração de municípios, predominantemente de pequeno porte, assemelhando-se bem com o perfil geral do Estado da Bahia, e por tratar-se de uma região próxima da capital, mas que possui características geográficas, econômicas e, principalmente, culturais muito próprias.

Do ponto de vista das mídias sociais, optou-se por pesquisar o uso do Facebook pela administração pública dos municípios. No Brasil, no ano de 2013, o Facebook foi o maior e mais importante site de rede social, sendo utilizado pela maioria dos brasileiros e possibilitando às organizações a montagem de uma extensa base de seguidores, além de incluir funcionalidades de diversos outros sites e a divulgação de informações em multimídias com o uso de vídeos, imagens e uso de aplicativos (Secom, 2012). Segundo o IBOPE (Rocha, 2013), o Facebook responde por 73,5\% da audiência das redes sociais no país. A Bahia se destaca como o estado de maior número de usuários do Facebook dentre todos os estados das regiões Nordeste, Norte e Centro-Oeste do Brasil (Serasa Experian, 2013).

A partir deste contexto, a coleta dos dados foi realizada por meio de acesso virtual, buscando a presença oficial dos municípios no Facebook para a análise de seus conteúdos. Foram observados, assim, os seguintes aspectos: presença e tipo de inserção no Facebook (fan page ou perfil), data da primeira postagem, quantidade de amigos ou seguidores, existência de identificação do administrador da fan page ou perfil, conteúdos das postagens (convites, fotos, links para notícias, documentos oficiais), interação com os usuários (publicações ou comentários feitos pelos usuários e respostas aos usuários) e adequação visual e da linguagem.

\section{Resultados da pesquisa}

\subsection{Território do Recôncavo}

A reflexão de que o estudo de novas práticas traz consigo desafios de difícil previsão aponta para a importância de escolher uma metodologia com relativa plasticidade deixando fronteiras abertas para explorações maiores. Para a realização deste trabalho foi analisada a utilização do Facebook pelas Prefeituras Municipais localizadas no Território de Identidade do Recôncavo, no Estado da Bahia, Brasil.

Visando uma melhor gestão das diversas regiões do Estado, a Secretaria do Planejamento do Estado da Bahia [Seplan] (2013) distribuiu os 417 municípios baianos em territórios de identidade constituídos a partir da especificidade de cada região. Segundo a Seplan (2013):

O território é conceituado como um espaço físico, geograficamente definido, geralmente contínuo, caracterizado por critérios multidimensionais, tais como o ambiente, a economia, a sociedade, a cultura, a política e as instituições, e uma população com grupos sociais relativamente distintos, que se relacionam interna e externamente por meio de processos específicos, onde se pode distinguir um ou mais elementos que indicam identidade, coesão social, cultural e territorial.

O Território de Identidade do Recôncavo, ou simplesmente Território Recôncavo, possui uma área de 5.250,51 $\mathrm{Km}^{2} \mathrm{e}$ uma população de 649.425 habitantes distribuída entre 20 municípios: Cabaceiras do Paraguaçu, Cachoeira, Castro Alves, Conceição do Almeida, Cruz das Almas, Dom Macedo Costa, Governador Mangabeira, Maragogipe, Muniz Ferreira, Muritiba, Nazaré, Santo Amaro, Santo Antônio de Jesus, São Felipe, São Félix, São Francisco do Conde, São Sebastião do Passé, Sapeaçu, Saubara e Varzedo (Seplan, 2013). A população média dos municípios do território, em 2013 
(IBGE, 2013), era de 32.471 pessoas, sendo Santo Antônio de Jesus o maior município em população, com um total de 99.407 habitantes, e Dom Macedo Costa o de menoor população, com apenas 4.127 habitantes.

Considerado a mais antiga, tradicional e organizada região do Estado da Bahia, o Território Recôncavo tem recebido, nos últimos anos, investimentos importantes da área de educação e infraestrutura, com destaque para a implantação da Universidade Federal do Recôncavo da Bahia (UFRB) e do Estaleiro de São Roque do Paraguaçu.

\subsection{Presença e tipo de inserção no Facebook}

Na avaliação da presença no Facebook, foi constatado que dos 20 municípios integrantes do Território Recôncavo, 14 prefeituras municipais (70\%) utilizam o Facebook para comunicação com a população, sendo que 11 mantêm páginas, ou fan pages, e 3 possuem perfis. Perfis são o que usuários, pessoa física, com e-mail podem criar ao se cadastrarem no Facebook. Segundo Pereira (2010), um perfil no Facebook está dividido em três partes que são o "wall" (mural para postagem de mensagens rápidas e visualizadas por todos), que contém informações de atividades recentes do usuário, inclusive de aplicativos e recados de outras pessoas; o "info", com informações do usuário; e o "photos" que abriga os álbuns dos usuários. Conforme Moch (2011), as fan pages são espaços com grupos de fãs, onde os consumidores podem interagir com suas marcas preferidas. No caso deste trabalho a interação estudada é entre o cidadão usuário e a administração pública.

Ainda sobre a utilização do Facebook como meio oficial de comunicação de prefeituras municipais, constata-se que 6 municípios (30\%) ainda não estão inseridas nesta mídia.

Chama a atenção que, com exceção da Prefeitura de Muritiba, que possui dois perfis, um com primeira postagem em março de 2012 e outro com primeira postagem em janeiro de 2013, todas permaneceram com o mesmo perfil ou fan page.

\subsection{Data da primeira postagem}

A Prefeitura Municipal de São Felipe foi a primeira do Território Recôncavo a utilizar o Facebook (tabela 1), efetuando sua primeira postagem em dezembro de 2010 e permanecendo desde então com o mesmo endereço de perfil. Já a Prefeitura Municipal de Dom Macedo Costa, menor município da região, foi a última, dentre as estudadas, a aderir à mídia social em questão, realizando sua primeira postagem em março de 2013.

Ainda quanto à análise da data de primeira postagem, observou-se que em 58,3\% dos casos estudados a utilização do Facebook iniciou-se durante a gestão 2009-2012 dos governos municipais. É possível perceber, portanto, que $41,7 \%$ dos municípios aderiram ao uso do Facebook apenas a partir dos primeiros meses de 2013, demonstrando um crescimento acentuado no uso da ferramenta nesse período mais recente.

\subsection{Quantidade de amigos ou seguidores}

É possível avaliar a popularidade dos perfis ou fan pages dos municípios estudados por meio da observação do número de usuários do Facebook que se tornaram amigos ou seguidores das respectivas páginas. Neste sentido, foi observado (tabela 1) que a fan page do município de São Francisco do Conde se destaca dentre as estudadas por apresentar 3.482 seguidores, representando um percentual de $9,5 \%$ da população do município estimado pelo IBGE (2013). O município com maior número absoluto de seguidores de sua fan page, e também o de maior população do Território Recôncavo, é Santo Antônio de Jesus, com 3.889 seguidores, correspondendo a 3,9\% de seu número total de habitantes. No outro extremo, destaque-se o município de Cachoeira, com mais de 34 mil habitantes, que possui apenas três seguidores em sua fan page (tabela 1).

Tabela 1 - Panorama dos Municípios Usuários do Facebook - Território Recôncavo/ Bahia / Brasil

\begin{tabular}{|l|c|c|c|c|c|}
\hline Municípios usuários do Facebook & $\begin{array}{c}\text { População do } \\
\text { município }\end{array}$ & \multicolumn{2}{|c|}{ Amigos/seguidores } & $\begin{array}{c}\text { Data da primeira } \\
\text { postagem }\end{array}$ \\
\hline Cabaceiras do Paraguaçu & 18.713 & 694 & 3,7 & jan/13 \\
\hline Cachoeira & 34.244 & 3 & 0 & fev/13 \\
\hline Conceição do Almeida & 18.644 & 299 & 1,6 & fev/13 \\
\hline Cruz das Almas & 63.299 & 887 & 1,4 & jan/13 \\
\hline Dom Macedo Costa & 4.127 & 36 & 0,9 & mar/13 \\
\hline Governador Mangabeira & 21.125 & 248 & 1,2 & fev/12 \\
\hline Muritiba (fan page 2012) & 30.635 & 1.111 & 3,6 & mar/12 \\
\hline Muritiba (fan page 2013) & 30.635 & 221 & 0,7 & jan/13 \\
\hline Santo Amaro & 61.407 & 476 & 0,8 & mai/12 \\
\hline Santo Antônio de Jesus & 99.407 & 3.889 & 3,9 & jun/12 \\
\hline São Felipe & 21.513 & 219 & 1 & dez/10 \\
\hline São Francisco do Conde & 36.677 & 3.482 & 9,5 & nov/12 \\
\hline São Sebastião do Passé & & 45.090 & 836 & 1,9 & jan/13 \\
\hline Sapeaçu & 17.594 & 96 & 0,5 & jan/13 \\
\hline Saubara & 12.078 & 442 & 3,7 & dez/12 \\
\hline
\end{tabular}

Fonte: IBGE, 2013 / Pesquisa de campo. 
Considerando-se, por fim, o total de seguidores das respectivas fan pages ou perfis oficiais de todos os 14 municípios do Território Recôncavo inseridos no Facebook., este número equivale a apenas $2,5 \%$ do total da população.

\subsection{Identificação da administração da fan page}

Quanto ao quesito informações sobre os responsáveis pela administração da página, é de chamar a atenção que, de todos os municípios estudados, apenas o de São Sebastião do Passé apresentava alguns desses dados, por ocasião da realização da pesquisa, incluindo-se aí os respectivos telefones e e-mail para contato na fan page. Nenhum dos demais municípios apresentava qualquer informação sobre responsáveis pela página, fossem eles oficiais ou mesmo terceirizados.

\subsection{Conteúdo das postagens}

No que se refere ao conteúdo das postagens, $100 \%$ dos municípios que utilizam o Facebook no Território Recôncavo postam sobre assuntos relacionados com a gestão pública local. Dentre os tipos mais constantes de postagens estão Fotos $(93,34 \%)$ de locais do município, como prédios públicos, monumentos, paisagens naturais, obras recém inauguradas e realizadas pela atual gestão, assim como registros de festas populares, eventos esportivos e ações da gestão pública em escolas e centros de saúde; Convites $(86,67 \%)$ para inaugurações de obras públicas, comemorações e festas populares, com destaque para aniversário da cidade, shows artísticos e as tradicionais festas de São João, São Pedro e Carnaval; Links $(66,67 \%)$ para notícias veiculadas em sites ou blogs de órgãos da prefeitura, órgãos estaduais e federais, a exemplo da Secretaria da Fazenda do Estado da Bahia, Receita Federal do Brasil e do Portal da Transparência; e documentos oficiais (13\%) dos órgãos públicos, a exemplo do Diário Oficial do Município.

\subsection{Interação/interatividade}

Diversos autores definem o termo interatividade, como, por exemplo, a participação ativa do beneficiário de uma transação de informação, conforme aponta Lévy (1999). Recuero (2009) afirma que a interação é a matéria-prima das relações e dos laços sociais, já Primo (2007, p. 5) estabelece que interação seja entendida como "ação entre" os participantes do encontro (inter+ação).

Considerando o cenário 2.0, a interação com o usuário foi medida por meio da presença de publicações realizadas por cidadãos usuários, da presença de comentários feitos por cidadãos usuários e pela existência de respostas a tais publicações e/ou comentários nos perfis ou fan pages dos municípios estudados, levando-se em conta a possibilidade concreta do encontro (conversa entre o cidadão e a administração pública).

Observou-se que em $53 \%$ das fan pages ou perfis existiam publicações de usuários e em $60 \%$ havia comentários de usuários. Entretanto, em apenas 20\% existia resposta da parte da administração pública acerca das colocações ou questionamentos feitos pelos usuários. Ressaltamos que em nenhum dos municípios estudados observou-se a presença concomitante dos três parâmetros de interação (publicação, comentário e resposta).
Os achados quanto à interação coadunam com as considerações feitas por Terra (2012), nas quais a autora aponta que, embora os usuários no contato com as organizações via mídias sociais queiram ser ouvidos, respondidos e bem tratados em um curto espaço de tempo, o que se observa é que as organizações estão mais dispostas a falar e a se autopromover do que ouvir às suas demandas.

\subsection{Adequação visual e linguagem}

Não foram observadas inadequações visuais ou de linguagem nos perfis ou fan pages estudados. Para chegar a esta conclusão foram lidas todas as postagens com a finalidade de identificar utilização de linguagem vulgar, erros crassos de idioma ou imagens sem aderência ao contexto da administração pública.

Para ilustrar seus perfis e fan pages, $66,7 \%$ das prefeituras utilizam a logomarca de governo, $20 \%$ usam brasão do município e 13,3\% lançam mão de fotos do município. Portanto, adequados ao parágrafo $1^{\mathrm{o}}$ do Artigo 37 da Constituição Federal brasileira no qual se lê:

A publicidade dos atos, programas, obras, serviços e campanhas dos órgãos públicos deverá ter caráter educativo, informativo ou de orientação social, dela não podendo constar nomes, símbolos ou imagens que caracterizem promoção pessoal de autoridades ou servidores públicos.

\section{Conclusões}

Mais do que uma ferramenta de incentivo aos relacionamentos humanos, as redes sociais e, num nível mais abrangente, as mídias sociais têm se mostrado um precioso meio de comunicação entre organizações e seus públicos. A administração pública também tem lançado mão desta ferramenta, numa tendência de aproximar os gestores dos cidadãos, tornando o fluxo de informações mais profícuo e eficiente.

Foi constatado nesta pesquisa que $70 \%$ dos municípios do Território Recôncavo, no Estado da Bahia, Brasil, já tinham suas respectivas administrações públicas inseridas no Facebook no início de 2013, sendo que 79\% desses utilizam fan pages e $21 \%$ possuem perfis. Chama a atenção o fato de $30 \%$ dos municípios do Território ainda não atuarem no Facebook na mesma ocasião.

O primeiro município da região a utilizar Facebook como meio de comunicação oficial foi São Felipe, em dezembro de 2010. No entanto, mais de $41 \%$ dos municípios só começaram a usar nos primeiros meses de 2013.

0 número de seguidores/amigos das fan pages e perfis em atividade na região corresponde a apenas $2,5 \%$ da população, sendo que o município que apresenta maior percentual é São Francisco do Conde, com 9,5\% de seus habitantes, e o de menor participação é Cachoeira, com $0 \%$ (apenas 3 seguidores). Um ponto que chama a atenção é a ausência de identificação dos responsáveis pelas páginas, com exceção apenas do município de São Sebastião do Passé.

Notadamente todos os municípios utilizam a mídia social para postar assuntos relacionados com a gestão pública local. Quanto à interação, em $60 \%$ das fan pages e perfis havia comentários de usuários, porém, somente foram encontradas resposta da parte da administração pública 
sobre os comentários ou questionamentos feitos pelos usuários em apenas $20 \%$.

Por fim, foi constatada uma boa adequação visual nas diversas fan pages e perfis analisados, com uso de boa linguagem, além do uso de fotos, logomarcas de governo, brasões dos municípios.

Espera-se que os dados e informações levantados neste estudo possam permitir uma visão mais realista e objetiva de como municípios utilizam mídias sociais, quando utilizam, para por em prática a comunicação oficial com seus cidadãos, e que esses resultados possam auxiliar o planejamento e desenvolvimento de ações por parte dos que atuam diretamente com comunicação pública oficial e profissionais que lidam com o assunto mídias sociais e suas tendências e aplicações. Também espera-se que, para os pesquisadores da área, possam servir de subsídios para a compreensão e análise da utilização de mídias sociais dentro da administração pública, no que diz respeito às suas potencialidades e implicações.

Por tratar-se de um tema longe de ser esgotado, são apresentadas as seguintes sugestões de novos estudos: atualização da pesquisa anualmente; pesquisar os demais territórios de identidade do Estado da Bahia, possibilitando traçar um comparativo entre os mesmos; investigar e analisar que outras mídias sociais têm sido utilizadas pelos municípios e quais os resultados alcançados; traçar um comparativo do uso de mídias sociais e mídias tradicionais pelas prefeituras municipais; avaliar a redução de custos, caso exista, e o impacto nos orçamentos das prefeituras com o uso de mídias sociais; conhecer a opinião das respectivas populações quanto à eficiência e qualidade das mídias sociais utilizadas pelas prefeituras; investigar e analisar o uso de mídias sociais por parte do governo do estado.

\section{Referências}

Arnaut, R. D., Hipólito, L., Nogueira, F., Rodrigues, B., Uhieda, S., et al. (2011). Era transmídia. Revista GEMInIS, ano 2, 2, 259-275. Recuperado em 5 de Junho, 2014, de http://www.revistageminis.ufscar.br/index.php/geminis/article/v iew/93/pdf.

Boaria, F., dos Anjos, S. J. G. \& Raye, R. L. (2014). A aplicação do emarketing nas redes hoteleiras do Brasil. Tourism \& Management Studies, 10(2), 116-122.

Bresser Pereira, L. C. (1999). Reflexões sobre a reforma gerencial brasileira de 1995. Revista do Serviço Público, 50(4), 5-28

Castells, M. (2005). Sociedade em Rede. São Paulo: Paz e Terra.

Cole, R. (2009). Social media: what does it mean for public managers?. PM Magazine, 9(9), 8-12. Recuperado em 2 Junho, 2014, de

http://webapps.icma.org/pm/9109/public/cover.cfm?author=rick $\% 20$ cole\&title=social $\% 20$ media $\% 3 \mathrm{~A} \% 20$ what $\% 20$ does

$\% 20$ it $\% 20$ mean\%20for\%20public\%20managers?

Conselho de Defesa Nacional. (2012). Portaria № 38, de 11 de junho de 2012. Estabelece as diretrizes para o uso seguro das redes sociais na Administração Pública Federal. Diário Oficial da União da República Federativa do Brasil. Ano CXLIX, no 119, 21 jun. 2012. seção 1, p. 3., Brasília. Recuperado em 2 Junho, 2014, de http://pesquisa.in.gov.br/imprensa/jsp/visualiza/index.jsp?data= $21 / 06 / 2012$ \&jornal=1\&pagina $=3 \&$ totalArquivos $=68$.

Correa, E. S. (2009). A Comunicação Digital nas organizações: tendências e transformações. Organicom, ano 6, Edição Especial, $10 / 11$, 161-167. Recuperado em 4 de Junho, 2014, de http://www.revistaorganicom.org.br/sistema/index.php/organico $\mathrm{m} /$ article/view/201.
Danis, C., Bailey, M., Christensen, J., Ellis, J., Erickson, T., Farrell, R. \& Kellogg, W. (2009). Mobile applications for the next billions: a social computing application and a perspective on sustainability. Recuperado em 2 Junho, 2014, de http://jellis.org/work/nbimtsdc2009.pdf.

Dizard, W. P. Jr. (2000). A Nova Mídia - a comunicação de massa na era da informação. Rio de Janeiro: Jorge Zahar Ed..

Govtec - Government Technology. (2012). The best social media cities - local governments ranked - 29 MAR 2012. Recuperado em 7 Junho, 2014, de http://www.govtech.com/wireless/Best-SocialMedia-Cities-2012.html.

Instituto Brasileiro de Geografia e Estatística. (2013). Estimativas da População Residente nos Municípios Brasileiros com Data de Referência em 1o de Julho de 2013. Diretoria de Pesquisas - DPE Coordenação de População e Indicadores Socias, IBGE, 2013 Recuperado em 8 Junho, 2014, de ftp://ftp.ibge.gov.br/Estimativas_de_Populacao/Estimativas_2013/ estimativa_2013_dou.pdf.

Kaplan, A. M. \& Haenlein, M. (2010). Users of the world, unite! The challenges and opportunities of social media. Business Horizons, 53, 59-68.

Kes-Erkul, A. \& Erkul, R. (2009). Web 2.0 in the Process of eparticipation: The Case of Organizing for America and the Obama Administration. National Center for Digital Government Working Paper Series, 9(1), 1-19. Recuperado em 21 Julho, 2015, de http://scholarworks.umass.edu/cgi/viewcontent.cgi?article=1031 \&context=ncdg.

Lévy, P. (1999). Cibercultura. São Paulo: Editora 34

Marteleto, R. M. (2010). Redes sociais, mediação e apropriação de informações: situando campos, objetos e conceitos na pesquisa em ciência da informação. UFPR. Recuperado em 2 Outubro, 2013, de http://www.brapci.ufpr.br/documento.php?dd0 $=0000009339 \& d d$ $1=9 \mathrm{e} 855$.

Ministério da Administração Federal e Reforma do Estado. (1995). Plano Diretor da Reforma do Aparelho do Estado. Brasília: Câmara de Reforma do Estado.

Mintzberg, H.; Ahlstrand, B. \& Lampel, J. (2000). Safári de estratégia: um roteiro pela selva do planejamento estratégico. Porto Alegre: Bookman.

Moch, T. (2011). O que é uma fan page (página da fãs)?. Recuperado em 10 Dezembro, 2013, de http://www.webinterativa.com.br/blog/social-media-

marketing/o-que-e-uma-fan-page-pagina-de-fas/.

Motta, P. R. (2007). A modernização da administração pública brasileira nos últimos 40 anos. RAP, edição especial comemorativa 1967-2007, 87-96.

Pereira, A. P. (2010). Orkut $x$ Facebook: quais as principais diferenças? Recuperado em 10 Dezembro, 2013, de http://www.tecmundo.com.br/facebook/3937-orkut-x-facebookquais-as-principais-diferencas-.htm.

Pinto, M. (2012). Como organizações públicas tratam o uso das mídias sociais no ambiente de trabalho. Recuperado em 5 Junho, 2014, de http://www.ninocarvalho.com.br/infograficos/como-asorganizacoes-publicas-lidam-com-o-uso-das-midias-sociais-noambiente-de-trabalho/.

Primo, A. (2007). 0 aspecto relacional das interações na web 2.0. ECompós, 9, 1-21.

Recuero, R. (2009). Redes Sociais na Internet. Porto Alegre: Sulina.

Rezende, D. A. \& Castor, B. V. J. (2006). Planejamento estratégico municipal: empreendedorismo participativo nas cidades, prefeituras e organizações públicas. 2. Rio de Janeiro: Brasport.

Rezende, D. A. \& Leite, L. O. (2009). Sistemas e tecnologia da informação e suas relações com planos e gestão municipal: análises em 110 prefeituras brasileiras. EnADI/ANPAD. Recuperado em 5 Junho, 2014, de http://www.anpad.org.br/diversos/trabalhos/EnADI/enadi_2009/ 2009_ENADI42.pdf.

Rocha, C. (2013). Em 2013, Brasil vira potência das redes sociais. Caderno Economia. O Estado de São Paulo, 24.12.2013. Recuperado em 2 Junho, 2014, de http://economia.estadao.com.br/noticias/geral,em-2013-brasilvira-potencia-das-redes-sociais-imp-,1111960. 
Romano, F. M., Chimenti, P., Rodrigues, M. A. S., Hupsel, L. F. \& Nogueira, R. (2012). O Impacto das mídias sociais digitais na comunicação organizacional das empresas. V EMA - Curitiba 20 a 22.05.2012, p. 1a16. Recuperado em 4 Junho, 2014, de http://www.anpad.org.br/diversos/trabalhos/EMA/ema_2012/20 12_EMA186.pdf.

Saad Correa, E. (2009). Comunicação digital e novas mídias institucionais. In: M. M. K. Kunsch (org.). Comunicação organizacional (pp. 317-335). São Paulo: Saraiva.

Secretaria de Comunicação da Presidência da República (Secom). (2012). Manual de orientação para atuação em redes sociais. Recuperado em 30 Outubro, 2013, de http://www.secom.gov.br/sobre-a-secom/acoes-e-

programas/publicacoes/manuais-e-marcas/manual-de-redessociais.

Secretaria do Planejamento do Estado da Bahia (Seplan). (2013). Territórios de identidade. Recuperado em 4 Junho, 2014, de http://www.seplan.ba.gov.br/territorios-de-identidade/mapa.

Serasa Experian. (2013). Facebook lidera top 10 redes sociais mais visitadas no Brasil em abril, segundo Hitwise. Recuperado em 5 Junho, 2014,

de http://www.serasaexperian.com.br/release/noticias/2013/noticia _01214.htm.

Smith, T. (2009). The Social Media Revolution. International Journal of Marketing, v. 51, 4, 559-561. Recuperado em 21 Julho, 2015, de http://www.socialnety.pl/wp-

content/uploads/2015/01/The_social_media_revolution.pdf

Storch, S. (2007). As redes sociais já fazem parte do nosso jeito de pensar. Instituto Intranet Portal. Recuperado em 2 Junho, 2014, de http://intranetportal.org.br/wp/2007/10/as-redes-sociais-jafazem-parte-de-nosso-jeito-de-pensar/.

Terra, C. F. (2012). A atuação das organizações nas mídias sociais e sua relação com a comunicação organizacional. In: I. L. Oliveira e M. Marchiori, Redes sociais, comunicação, oganizações (pp. 201-215). Manual de conduta em mídias sociais embrapa. São Caetano do Sul: Difusão Editora.

Submetido: 31.05 .2014

Aceite: 26.11 .2014 